\title{
Theoretical Study of the Effect of Water Clusters on the Enol Content of Acetone as a Model for Understanding the Effect of Water on Enolization Reaction
}

\author{
Zahra Tohidi Nafe \\ University of Zanjan \\ Nematollah Arshadi ( $\square$ narshadi@znu.ac.ir) \\ University of Zanjan https://orcid.org/0000-0001-9460-0952
}

\section{Research Article}

Keywords: Enol content, DFT calculations, Water clusters, Hydrogen-bonded assembly, Water-clustered tautomer, Enolization reaction

Posted Date: June 8th, 2021

DOl: https://doi.org/10.21203/rs.3.rs-577869/v1

License: (c) (i) This work is licensed under a Creative Commons Attribution 4.0 International License.

Read Full License

Version of Record: A version of this preprint was published at Structural Chemistry on July 29th, 2021. See the published version at https://doi.org/10.1007/s11224-021-01813-y. 


\section{Abstract}

The enolization of simple carbonyl compounds is a key reaction for many chemical and biochemical processes. Numerous theoretical and experimental studies have been done to probe aspects of the mechanism of this reaction. In this work, the effect of small water clusters, $\left(\mathrm{H}_{2} \mathrm{O}\right)_{n}: \mathrm{n}=1-9$, on the enol content of acetone is investigated by using density functional theory calculations at the M06 level of theory in the gas and solution phases. The calculations indicated that the formation of hydrogen-bonded assemblies between water clusters and both tautomers of acetone affect the enolization reaction. Among them, the trimeric water cluster has the highest binding energy difference $\left(D E_{b}\right)$ in the solution phase and greatly shift the equilibrium in the favor of the enol form. The results also shown that under this condition, the enol content of acetone increased by decreasing the polarity of the solvent. The practical conclusion of this study is that the enol content of carbonyl compounds can be maximized only by addition a defined amount of water.

\section{Introduction}

The study of enolization or keto-enol tautomerism of ketones from experimental and theoretical aspects is an active area of research due to its essential role in the chemical and biochemical processes [1-4]. Experimental data reveal that the enol content, $K_{e}$ ([enol]/[ketone]), of simple ketones, is low even in pure form and in their aqueous solutions. It is not over $1-2 \%[5,6]$. The enol content value $\left(p K_{e}\right)$ of acetone were reported by other authors are given for comparison, Table 1.

Table 1

Some reported values for enol content value of acetone at $25^{\circ} \mathrm{C}$

\begin{tabular}{|c|c|c|c|c|c|}
\hline Author & $K_{e}$ & $\mathrm{p} K_{e}$ & Author & $K_{e}$ & $\mathrm{p} K_{e}$ \\
\hline Schwarzenbach ${ }^{\mathrm{a}}$ & $2.5 \times 10^{-4}$ & 3.6 & Gero $^{b}$ & $1.5 \times 10^{-4}$ & 3.82 \\
\hline Bell $^{a}$ & $<10^{-4}$ & 4 & Hine ${ }^{c}$ & $2.4 \times 10^{-7}$ & 6.62 \\
\hline Chiang $^{\mathrm{a}}$ & $6 \times 10^{-9}$ & 8.22 & Sunner $^{d}$ & $1.6 \times 10^{-4}$ & 3.8 \\
\hline Dubois $^{a}$ & $3.5 \times 10^{-7}$ & 6.46 & Osugie & $4.0 \times 10^{-2}$ & 1.4 \\
\hline Kresge $^{\mathrm{a}}$ & $4.6 \times 10^{-9}$ & 8.34 & Msiedeen $^{f}$ & $3.5 \times 10^{-11}$ & 10.5 \\
\hline
\end{tabular}

The keto form is thermodynamically more stable than the enol form, but some factors, such as dielectric constant and hydrogen bond-forming ability of solvent, temperature, concentration, catalyst, and substituent groups, shift the equilibrium in favor of the enol form. For instance, more polar keto form in a polar solvent is the predominant tautomeric form due to the solvation effect [8, 15-21]. 
Enol content of carbonyl compounds has been traditionally determined by the Kurt-Meyer titration method but when the amount of enol form is less than $1 \mathrm{ppm}$ this technique doesn't work well. In that case, spectroscopic methods, flash photolysis, thermochemical and kinetic methods can be used $[6,7,14,22-$ 26]. Also, some theoretical studies have been carried out as well [27-32].

Researchers are interested in designing systems that improve $K_{e}$ of mono-carbonyl compounds. Recently, water was used as a catalyst to increase the rate of enolization reactions. It is found that free energy of activation of keto-enol tautomerization process decreases in the presence of one or two water molecules $[16,17,21,28,31]$. It also seems that water molecules control the pathway of aldol reaction by decreasing or increasing the formation rate of enol intermediate, in other words, the enol content of the carbonyl compound. In our previous work, we theoretically found that the aldol reaction in the presence of L-proline as a catalyst can proceed concurrently through enamine-based and enol-based pathways in DMSO as solvent at room temperature. But, the formation of the enol intermediate predominates upon the addition of water [33]. Also, the product of L-proline-catalyzed aldol reaction between acetone and 4nitrobenzaldehyde in the presence of water shows good yield and weak stereoselectivity but in the absence of water, the results reversed [34, 35].

Now the question arises, does water change the reaction mechanism? Do water molecules lonely or together affect the reaction rate? To answer these questions, we calculated the enol content of acetone in the presence of one molecule of water and some small water clusters (WCs) using DFT calculations.

\section{Computational Method}

All the calculations were performed using the Spartan ' 16 software package [36]. The enol content of acetone was examined in the presence of one molecule of water and some small WCs, $\left(\mathrm{H}_{2} \mathrm{O}\right)_{n}, n=2-9$, in the gas phase and acetone and DMSO as a solvent at room temperature, Fig. 1 [37-39].

The key idea of the work is based-on the formation of a hydrogen-bonded assembly between a WC and both tautomeric forms of acetone - water-clustered tautomers - and thus, hydrogen bonding plays an important role in the stability and behavior of the assemblies. The computations were done using the M06, the hybrid functional of Truhlar, which can account for dispersion interactions and describe some weak non-covalent interactions such as hydrogen bonding [40-42]. So, all calculations were carried out at the M06/6-31+G** level of theory in the gas phase and acetone and DMSO as a solvent at room temperature. Solvent effects were included using the SM8 solvation model.

The enol content $\left(K_{e}\right)$ was calculated based on the thermodynamic properties of the assembly of both tautomeric forms of acetone with the same water cluster by the following equation:

$$
K_{e}=e^{\left(-\frac{\Delta G}{R T}\right)}
$$


, where $K_{e}$ is the equilibrium constant between the tautomers, the gas constant R is $8.314 \mathrm{~J} / \mathrm{mol}$ and the temperature $\mathrm{T}$ is $298.15 \mathrm{~K}$.

Frequency calculation for characterizing stationary point was calculated at the same level. No imaginary frequency reveals that all of the structures are in ground states.

\section{Results And Discussion}

The water-clustered tautomers including WCs, $\mathbf{1 - 5}, \mathbf{8}$ and $\mathbf{9}$, and the keto form (K) of acetone, $\mathbf{K}^{\mathrm{n}}$, show one hydrogen bond between its oxygen atom and the WCs. But, in two other assemblies including 6 and 7, the acetone molecule enters into the structure of WC and forms a new mixed cluster. In all assemblies, the oxygen atom of one water molecule is slightly pointed to the hydrogen atom of the methyl group (aproton) of the acetone. This interaction may facilitate the formation of enol through proton abstraction by the nearby water molecule, Fig. 2 . The length of the hydrogen bond between $\mathbf{K}$ and $\mathbf{W C}\left(\mathrm{d}_{1}\right)$ and the distance between the water molecule and the a-proton of acetone $\left(d_{2}\right)$ are presented in Table 2.

In the water-clustered tautomers including enol form (E) of acetone, $E^{n}$, the hydroxyl group actively participate, mainly through two hydrogen bonds, to merge two structures into a new WC-like structure, Fig. 3. The length of two hydrogen bonds between $\mathbf{E}$ and $\mathbf{W C}\left(\mathrm{d}_{3}, \mathrm{~d}_{4}\right)$ are presented in Table 2. 
Table 2

The length of hydrogen bonds between $\mathbf{K}$ or $\mathbf{E}$ and $\mathbf{W C s}$ in $\mathbf{K}^{\mathrm{n}}$ or $\mathbf{E}^{\mathrm{n}}$ assemblies in the gas phase and solution at the M06/6-31+G** level of theory

\begin{tabular}{|c|c|c|c|c|c|c|c|}
\hline \multirow[t]{3}{*}{$K^{n}$} & & & & \multirow[t]{3}{*}{$E^{n}$} & & 8 & \\
\hline & \multicolumn{3}{|l|}{$\mathrm{d}_{1}-\mathrm{d}_{2}{ }^{*}(\AA)$} & & \multicolumn{3}{|l|}{$\mathrm{d}_{3}-\mathrm{d}_{4}(\AA)$} \\
\hline & Gas & Acetone & DMSO & & Gas & Acetone & DMSO \\
\hline $\mathrm{K}^{1}$ & $1.90-2.36$ & $1.85-2.76$ & $1.84-3.02$ & $E^{1}$ & 1.87- - & 1.83-- & 1.84- - \\
\hline$K^{2}$ & $1.82-2.27$ & $1.78-2.86$ & $1.78-2.87$ & $E^{2}$ & $1.82-1.98$ & $1.82-2.03$ & $1.83-2.02$ \\
\hline $\mathrm{K}^{3}$ & $1.77-2.46$ & $1.75-2.40$ & $1.75-2.41$ & $E^{3}$ & $1.76-1.84$ & $1.73-1.84$ & $1.74-1.84$ \\
\hline$K^{4}$ & $1.89-2.43$ & $1.83-2.69$ & $1.83-2.69$ & $E^{4}$ & $1.72-1.79$ & $1.71-1.82$ & $1.73-1.83$ \\
\hline$K^{5}$ & $1.94-2.50$ & $1.84-2.57$ & $1.84-2.54$ & $E^{5}$ & $1.75-2.00$ & $1.73-1.98$ & $1.74-1.98$ \\
\hline$K^{6}$ & $1.93-2.51$ & $1.76-3.33$ & $1.75-3.32$ & $E^{6}$ & $1.72-1.85$ & $1.71-1.87$ & $1.72-1.88$ \\
\hline $\mathrm{K}^{7}$ & $1.86-2.48$ & $1.83-2.62$ & $1.82-2.64$ & $\mathrm{E}^{7}$ & $1.66-1.92$ & $1.68-1.93$ & $1.70-1.93$ \\
\hline$K^{8}$ & $2.00-2.79$ & $1.78-3.02$ & $1.77-3.03$ & $E^{8}$ & $1.68-1.73$ & $1.68-1.76$ & $1.69-1.75$ \\
\hline$K^{9}$ & $1.85-2.54$ & $1.82-3.01$ & $1.82-3.05$ & $E^{9}$ & $1.65-1.89$ & $1.66-1.90$ & $1.67-1.90$ \\
\hline
\end{tabular}

According to Table 1 , the $\mathbf{K}^{3}$ assembly is geometrically much more prone to convert into the corresponding enol form, $\mathrm{E}^{3}$, in the solution phase. Because, it has the shortest distance between the aproton of acetone and the oxygen atom of water molecule $\left(\mathrm{d}_{2}\right)$.

The enol content of acetone in the presence of different WCs and in the gas phase or polar solvents were calculated based-on the Gibbs free energy of both assemblies, $\mathbf{K}^{\mathbf{n}}$ and $\mathbf{E}^{\mathbf{n}}$, Table 3 . It is expected that the increase in the water content leads to the rise of the enol content, $\mathrm{p} K_{e}$ of acetone because of the formation of hydrogen-bonded assemblies, $\mathbf{K}^{\mathrm{n}}$ and $\mathbf{E}^{\mathrm{n}}$, that stabilize both tautomeric forms of acetone. But the results showed that the number of water molecules of WCs and the solvent polarity have different effects on the enol content of acetone. The $\mathrm{p} K_{e}$ decreases with the increasing of solvent polarity. Therefore, the gas phase and non-polar solvents are more suitable condition for the enolization of acetone. 
In the gas phase, the WC including $\mathbf{5}$ water molecules behave differently from most other WCs. But, in the polar solvents, WC with $\mathbf{3}$ water molecules show such a behavior. For both cases the enolization of acetone is maximum. It seems that the WCs can stabilize the enol form more than the keto form by the formation of an assembly that includes a more stable WC-like segment, $E^{3}$ and $E^{5}$, Fig. 3. The significant decrease of enol content in $\mathbf{8}$ can be attributed to the high stability of its WC, which the cubic structure of it is disrupted by the formation of $\mathbf{E}^{8}$ assembly, Table 3, Fig. 3. $\left(\mathrm{H}_{2} \mathrm{O}\right)_{4}$ and $\left(\mathrm{H}_{2} \mathrm{O}\right)_{8}$ among the other small cyclic WCs have distinct stability. Therefore, as is seen in Fig. $2, \mathbf{K}^{4}$ and $\mathbf{K}^{8}$ show the resistance of the WC against insertion of carbonyl group [43]. Also, the relatively high enol content of $\mathbf{9}$ can be explained based-on the stabilizing interaction between water molecules and the hydroxyl group of enol form as a part of a stable WC [44].

Table 3

The enol content of acetone, $\mathrm{p} K_{e}$ in the presence of WCs in the gas phase and in acetone and DMSO as a solvent at M06/6$31+G * *$ levels of theory

\begin{tabular}{|llll|}
\hline $\mathrm{p} K_{e}$ & & & \\
\hline $\mathrm{n}$ & Gas & Acetone & DMSO \\
\hline 0 & 10.30 & 12.20 & 12.20 \\
\hline 1 & 10.20 & 10.80 & 11.50 \\
\hline 2 & 9.38 & 11.80 & 12.30 \\
\hline 3 & 9.06 & 9.08 & 9.24 \\
\hline 4 & 9.39 & 10.40 & 10.10 \\
\hline 5 & 8.00 & 9.48 & 10.30 \\
\hline 6 & 8.30 & 10.60 & 10.70 \\
\hline 7 & 8.34 & 10.40 & 10.60 \\
\hline 8 & 10.00 & 12.30 & 11.93 \\
\hline 9 & 8.69 & 9.43 & 9.35 \\
\hline The dipole moment of acetone and DMSO \\
\hline
\end{tabular}

are $2.62 \mathrm{D}$ and $3.96 \mathrm{D}$, respectively.

The orientation of orbitals and distance between the hydrogen atom of water and carbon-carbon double bond of the enol form in $\mathrm{E}^{5}$ is such that $\mathrm{H}-\pi$ bonding can form quite easily, Fig. 5 [45]. Therefore, this extra interaction stabilizes more the assembly and increases the $K_{e}$. 
The energy difference $(\Delta E)$ and the Gibbs free energy difference $(\Delta G)$ of $K^{n}$ and $E^{n}$ assemblies in different solvents are plotted against the number of water molecules (n) in the WCs, Fig. $6 \mathrm{a}$ and b. It is seen that the value of $\Delta \mathrm{E}$ for acetone in the gas phase is $13 \mathrm{kcal} / \mathrm{mol}$, which is in good agreement with experimental data, $13.9 \mathrm{kcal} / \mathrm{mol}$ [46-48]. The positive value of $\Delta \mathrm{E}$ indicates that the keto form is more stable than the enol one. Decreasing the $\Delta \mathrm{E}$ values mean the enolization process is facilitated by the WCs. In other words, the keto form of acetone is easier to convert to the enol form.

As shown in Fig. $6 \mathrm{a}$, the $\Delta \mathrm{E}$ values for 3, $\mathbf{5}$ and $\mathbf{9}$ assemblies in the polar solvents and for $\mathbf{5}$ and $\mathbf{9}$ assemblies in the gas phase are all minimum values. The above results are also confirmed by the Gibbs free energy difference $(\Delta G)$ graphs, Fig. $6 \mathrm{~b}$. It is seen that $\mathbf{3}$ for the solution phase and $\mathbf{5}$ for the gas phase are global minimum.

To confirm these results, the binding energy for the assemblies was calculated. The binding energy of an assembly $\left(E_{b}\right)$ is defined as:

$$
E_{b}=\left(n \times E_{H_{2} O}+E_{\text {tautomericform }}\right)-E_{\text {assembly }}
$$

, where $\mathrm{n}$ is the number of water molecules, $E_{\mathrm{H}_{2} \mathrm{O}}$ is the energy of a water molecule, $E_{\text {tautomericform }}$ is the energy of enol or keto form of acetone and $E_{\text {assembly }}$ is the energy of assembly, $\mathbf{K}^{\mathbf{n}}$ or $\mathbf{E}^{\mathbf{n}}$. The binding energy $\left(E_{b}\right)$ of each assembly $\left(\mathbf{K}^{\mathbf{n}}\right.$ and $\left.\mathbf{E}^{\mathbf{n}}\right)$ was plotted against the number of involved water molecules (n), Fig. 8a. From the graph, it is observed that the binding energy of each assembly is increased by increasing $\mathbf{n}$. Except in some few special cases, the binding energy of $\mathbf{E}^{\mathbf{n}}$ is a little higher than $\mathbf{K}^{\mathbf{n}}$ in both the gas phase and in solution, but the $\mathbf{K}^{\mathbf{n}}$ assemblies are still more stable than the $\mathbf{E}^{\mathbf{n}}$ ones. The $E_{b}$ values for the gas phase are higher than the solution phases. This is due to the interaction of water molecules with the solvent, which leads to weakening of the hydrogen bonds in the solution phase and, therefore, decreasing the stability of assemblies.

The binding energy difference $\left(\Delta E_{b}\right)$ of water-clustered tautomers is calculated by subtracting $E_{b}\left(\mathbf{K}^{\mathrm{n}}\right)$ from $E_{b}\left(\mathrm{E}^{\mathrm{n}}\right)$. This quantity is a good and reliable estimate of the overall energy for the enolization reaction of acetone. An energy diagram is created by plotting the $-\Delta E_{b}$ values as a function of $\mathbf{n}$, Fig. 8b. The $p K_{e}$ values are also plotted for comparison. As is seen, the enolization reaction of acetone is very favorable in the presence of 5 and 3 water molecules in the gas and solution phases, respectively. As mentioned before, in these cases, the binding energy of enol form of acetone is approaching to the keto form.

\section{Conclusions}

The results showed that the formation of mixed hydrogen-bonded assemblies between WCs and both tautomers of a carbonyl compound affect the rate of the enolization process, but may changes the mechanism of its self-aldol reaction in the presence of L-proline as a catalyst. Also, it is seen that the enol 
content increased by decreasing the polarity of the solvent, so the trend is gas > acetone > DMSO. It indicated that the shift of the keto-enol equilibrium toward the enol tautomer was highest in nonpolar solvents.

As reported earlier, the L-proline-catalyzed aldol reaction in organic solvents may proceed through two parallel competing reaction pathways $\left(\Delta \mathrm{E}_{\mathrm{a}} \sim 2 \mathrm{kcal} / \mathrm{mol}\right)$, the formation of enamine or the formation of enol as an intermediate, based on the amount of water. The enamine formation is a favorable pathway in the absence of water, but the addition of a small amount of water preferred the formation of enol [33].

According to our results, the enol content $\left(K_{e}\right)$ of acetone improved by adding a defined amount of water. Any changes in this defined amount of water cause a decrease in the enol formation. Thus, the enol formation pathway preferred the enamine one in the presence of an optimized amount of water. If this conclusion is correct, then the addition of a non-optimized amount of water to the proline-catalyzed aldol reaction solvent can have unpleasant effects on the yield and stereoselectivity of the reaction [34, 35]. This topic is currently under investigation in our group for more confirmation and development.

\section{Declarations}

Acknowledgments We gratefully acknowledge the Department of Chemistry of the University of Zanjan for its technical support of this work.

Funding: The authors did not receive support from any organization for the submitted work.

Conflicts of interest/Competing interests: There are no "Conflicts of Interest" to declare.

Availability of data and material: The authors confirm that the data supporting the findings of this study are available within the article and its supplementary material.

Code availability 'Not applicable'

Authors' contributions: The authors contributed equally to this work.

Ethics approval: 'Not applicable'

Consent to participate: 'Not applicable'

Consent for publication: 'Not applicable'

\section{References}

1. Berg JM, Tymoczko JL, Stryer L (2006) Lecture Notebook for Biochemistry. Macmillan

2. Knox WE (1953) The relation of liver kynureninase to tryptophan metabolism in pyridoxine deficiency. Biochem J 53:379-385 
3. Heidelberger C, Abraham EP, Leprovsky S (1949) Tryptophan metabolism; concerning the mechanism of the mammalian conversion of tryptophan into nicotinic acid. J Biol Chem 179:151-155

4. Rund JV, Plane RA (1964) Catalysis of the decarboxylation of dimethyloxaloacetate by manganese (II), nickel (II), and their complexes. J Am Chem Soc 86:367-371

5. Gero A (1954) Studies on enol titration. II. Enol contents of some ketones and esters in the presence of methanol. J Org Chem 19:1960-1970. https://doi.org/10.1021/jo01377a013

6. Domonkos L FR (1988) Identification of the enol content in some monoketones by an IR spectroscopic method. Monatsh Chem 119:177-186

7. Dubois JE, El-Alaoui M, Toullec J (1981) Kinetics and thermodynamics of keto-enol tautomerism of simple carbonyl compounds: An approach based on a kinetic study of halogenation at low halogen concentrations. J Am Chem Soc 103:5393-5401. https://doi.org/10.1021/ja00408a020

8. Chaing Y, Krege a J, Tang YS, Wirz J (1984) pKa and keto-enol equilibrium constant of acetone in aqueous solution. J Am Chem Soc 106:460-462. https://doi.org/10.1021/ja00314a055

9. Bell RP PWS (1966) The enol content and acidity of cyclopentanone, cyclohexanone, and acetone in aqueous solution. J Chem Soc B 241-243

10. Kresge AJ (2007) Generation and study of enols and other reactive species. Pure Appl Chem 63:213221. https://doi.org/10.1351/pac199163020213

11. Hine J, Arata K (1976) Keto-enol tautomerism. I. the calorimetrical determination of the equilibrium constant for keto-enol tautomerism for cyclopentanone. Bull Chem Soc Jpn 49:3085-3088

12. Sunner $S$ (1957) The heat of hydrolysis of i-propenyl acetate and m-cresyl acetate and the heat of enolization of acetone. Acta Chem Scand 1:1757-1760

13. Osugi J, Mizukami T, Tachibana T (1966) The effect of pressure on the keto-enol equilibria of acetone and cyclohexanone. Rev Phys Chem Jpn 36:8-19

14. Al-Msiedeen A, Al-Mazaideh G, Khalil S (2016) A theoretical study of the enol contents of cyclohexanone, cyclopentanone and acetone. Am Chem Sci J 13:1-8.

https://doi.org/10.9734/acsj/2016/25048

15. Shechter H, Collis MJ, Dessy R, Okuzumi YCA (1962) The effects of ring size on the rates of acid-and base-catalyzed enolization of homologous cycloalkanones and cycloalkyl phenyl ketones. J Am Chem Soc 84:2905-2910. https://doi.org/10.1021/ja00874a012

16. Malhotra S, Jaspal D, Khamparia S (2017) p-Chloroacetophenone: A study of enolization kinetics. Chem Eng Commun 204:1445-1451. https://doi.org/10.1080/00986445.2017.1367672

17. Malhotra S, Jaspal D (2013) Kinetics of enolisation of acetophenone and p-bromoacetophenone: Comparative studies. Bull Chem React Eng Catal 8:105-109. https://doi.org/10.9767/bcrec.8.2.4653.105-109

18. Hegarty AF, Dowling JP, Eustace SJ, McGarraghy M (1998) Enolization of aldehydes and ketones: Structural effects on concerted acid-base catalysis. J Am Chem Soc 120:2290-2296. https://doi.org/10.1021/ja9729544

Loading [MathJax]/jax/output/CommonHTML/jax.js 
19. Lienhard GE, Wang TC (1969) On the mechanism of acid-catalyzed enolization of ketones. J Am Chem Soc 91:1146-1153. https://doi.org/10.1021/ja01033a019

20. Novak P, Škare D, Sekušak S, Vikić-Topić D (2000) Substituent, temperature and solvent effects on keto-enol equilibrium in symmetrical pentane-1,3,5-triones. Nuclear magnetic resonance and theoretical studies. Croatica Chem Acta 73:1153-1170

21. Malhotra S, Jaspal D (2014) Kinetics of the enolisation reaction of m-nitro acetophenone catalyzed by amino acid. Bull Chem React Eng Catal 9:16-22. https://doi.org/10.9767/bcrec.9.1.5258.16-22

22. Bell RP, Gelles E, Moller E, A PRSL (1949) Kinetics of the base-catalyzed halogenation of some ketones and esters. Proc R Soc London Ser A Math Phys Sci 198:308-322. https://doi.org/10.1098/rspa.1949.0103

23. Keeffe JR, Kresge AJ (1990) The Chemistry of Enols. Wiley, Chichester

24. Zhang X, Malick D, Petersson GA (1998) Enolization enthalpies for aliphatic carbonyl and thiocarbonyl compounds. J Org Chem 63:5314-5317

25. Schweitzer GK, Benson EW (1968) Enol content of some beta-diketones. J Chem Eng Data 13(3):452-453

26. Wirz J (2010) Kinetic studies of keto-enol and other tautomeric equilibria by flash photolysis. Adv

27. phys Org Chem 44:325-356

28. Falklöf O (2015) Computational studies of photobiological keto-enol reactions and chromophores (Doctoral dissertation, Linköping University Electronic Press)

29. Jana K, Ganguly B (2018) DFT study to explore the importance of ring size and effect of solvents on the keto-enol tautomerization process of $\alpha$-and $\beta$-cyclodiones. ACS Omega 3:8429-8439. https://doi.org/10.1021/acsomega.8b01008

30. Lee D, Kim CK, Lee BS, et al (1997) A theoretical study on keto-enol tautomerization involving simple carbonyl derivatives. J Comput Chem 18:56-69. https://doi.org/10.1002/(SICI)1096987X(19970115)18:1<56::AID-JCC6>3.0.C0;2-Z

31. Noack WE (1979) An ab initio study of the keto-enol tautomerism. Theor Chim Acta 53:101-119. https://doi.org/10.1007/BF00548824

32. Cucinotta CS, Ruini A, Catellani A, Stirling A (2006) Ab initio molecular dynamics study of the ketoenol tautomerism of acetone in solution. Chem Phys Chem 7:1229-1234. https://doi.org/10.1002/cphc.200600007

33. Surendra S (2013) DFT studies of molecular structure, equilibrium constant for keto-enol tautomerism and geometrical isomerism (E-Z) of 2-amino-1-phenylpropan-1-one (Cathinone). Adv Appl Sci Res 4:147-153

34. Nobakht $\mathrm{Y}$, Arshadi $\mathrm{N}$ (2018) DFT study of the dual catalytic role of L-proline in the aldol reaction and the effect of water on it. J Mol Model 24:334. https://doi.org/10.1007/s00894-018-3851-0

35. Giacalone F, Gruttadauria M, Meo P, Lo et al (2008) New simple hydrophobic proline derivatives as hiahlv active and stereoselective catalvsts for the direct asymmetric aldol reaction in aqueous Loading [MathJax]/jax/output/CommonHTML/jax.js 
medium. Adv Synth Catal 350:2747-2760

36. Pihko PM, Laurikainen KM, Usano A et al (2006) Effect of additives on the proline-catalyzed ketonealdehyde aldol reactions. Tetrahedron 62:317-328

37. Wavefunction Inc (2017) Spartan'16, Windows version 2.0.7. Wavefunction Inc., Irvine

38. Grabowski SJ (2006) Hydrogen bonding: New insights. Springer

39. Sen S, Boda M, Venkat Lata S, Naresh Patwari G (2016) Internal electric fields in small water clusters $\left[\left(\mathrm{H}_{2} \mathrm{O}\right)_{\mathrm{n}}: \mathrm{n}=2-6\right]$. Phys Chem Chem Phys 18:16730-16737. https://doi.org/10.1039/c6cp02803a

40. The Cambridge energy landscape database, Molecular clusters, TIP4P and TIP5P water clusters http://www-wales.ch.cam.ac.uk/ wales/CCD.html. Accessed 21 May 2021

41. Zhao Y, Truhlar DG (2008) The M06 suite of density functionals for main group thermochemistry, thermochemical kinetics, noncovalent interactions, excited states, and transition elements: Two new functionals and systematic testing of four M06-class functionals and 12 other functionals. Theor Chem Acc 120:215-241

42. Wheeler SE, Moran A, Pieniazek SN, Houk KN (2009) Accurate reaction enthalpies and sources of error in DFT thermochemistry for aldol, Mannich, and a-aminoxylation reactions. J Phys Chem A 113:10376-10384

43. Hartley MK, Vine S, Walsh E et al (2015) Comparison of relative activation energies obtained by density functional theory and the random phase approximation for several claisen rearrangements. $J$ Phys Chem B 120:1486-1496

44. Liu X, Lu WC, Wang CZ, Ho KM (2011) Energetic and fragmentation stability of water clusters $\left(\mathrm{H}_{2} \mathrm{O}\right)_{n}$, n = 2-30. Chem Phys Lett 508:270-275. https://doi.org/10.1016/j.cplett.2011.04.055

45. Maheshwary S, Patel N, Sathyamurthy N et al (2001) Structure and stability of water clusters $\left(\mathrm{H}_{2} \mathrm{O}\right)_{n}$, $\mathrm{n}=8-20$ : An ab initio investigation. J Phys Chem A 105:10525-10537

46. Philp D, Robinson JMA (1998) A computational investigation of cooperativity in weakly hydrogenbonded assemblies. J Chem Soc Perkin Trans 2:1643-1650

47. Turecek F, Brabec L, Korvola J (1988) Unstable enols in the gas phase. Preparation ionization, energies, and heats of formation of (E)-and (Z)-2-buten-2-ol, 2-methyl-1-propen-1-ol, and 3-methyl-2buten-2-ol. J Am Chem Soc 110:7984-7990

48. Holmes JL, Lossing FP (1982) Heats of formation of ionic and neutral enols of acetaldehyde and acetone. J Am Chem Soc 104:2648-2649

49. Zhang X-M, Malick D, Petersson GA (1998) Enolization enthalpies for aliphatic carbonyl and thiocarbonyl compounds. J Org Chem 63:5314-5317

\section{Figures}


80

2

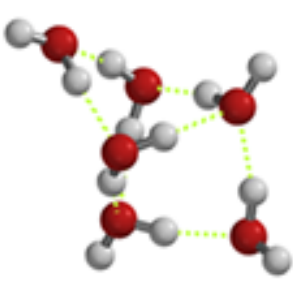

6

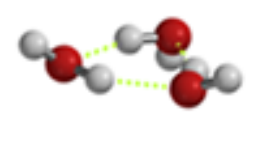

3 of

4

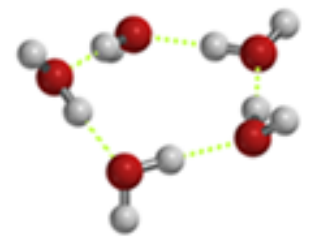

5

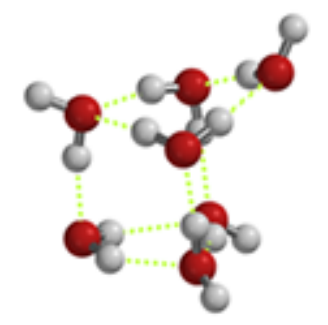

7

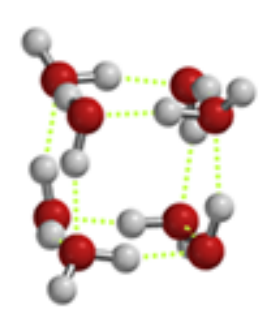

8

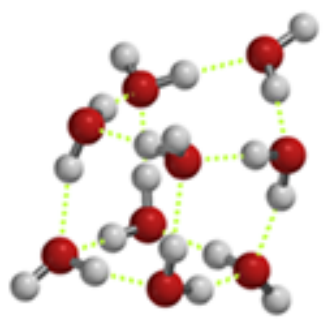

9

Figure 1

The most stable structure of used small WCs, $(\mathrm{H} 2 \mathrm{O}) \mathrm{n}, \mathrm{n}=2-9$.

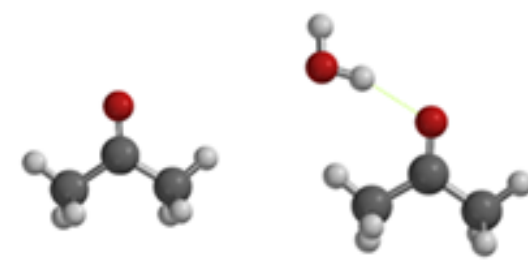

$\mathbf{K}^{0}$
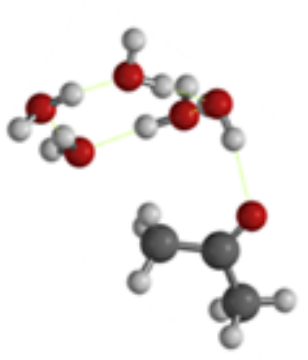

$\mathbf{K}^{5}$
$\mathbf{K}^{1}$

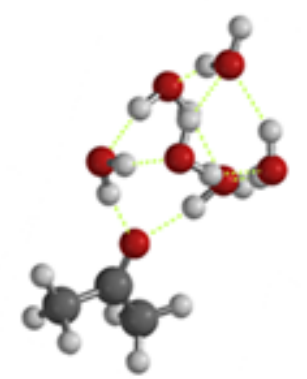

$\mathbf{K}^{6}$

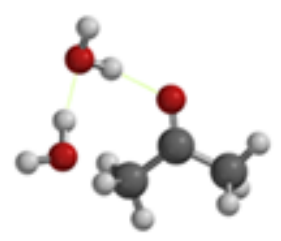

$\mathbf{K}^{2}$

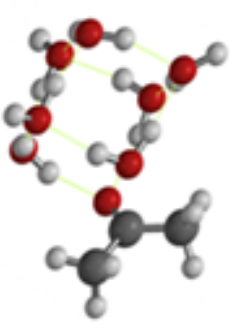

$\mathbf{K}^{7}$

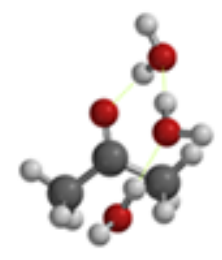

$\mathbf{K}^{3}$

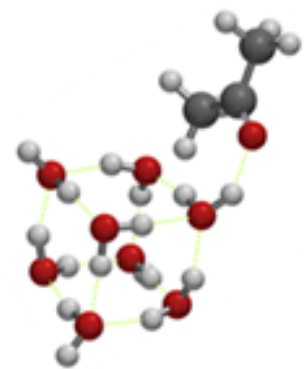

$\mathbf{K}^{\mathrm{s}}$

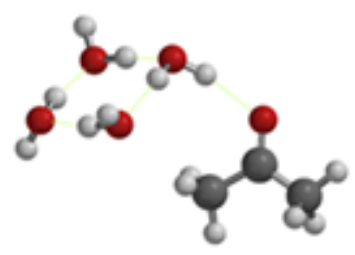

$\mathbf{K}^{4}$

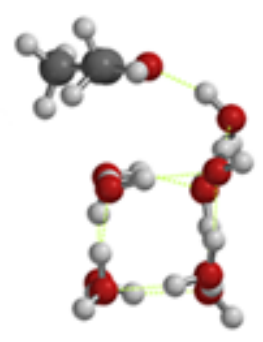

$\mathbf{K}^{9}$

Figure 2

The structures of K-WC assemblies in the gas phase, Kn, n: number of water molecules of WC; $n=0-9$. 


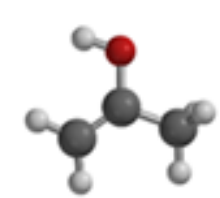

$\mathbf{E}^{0}$

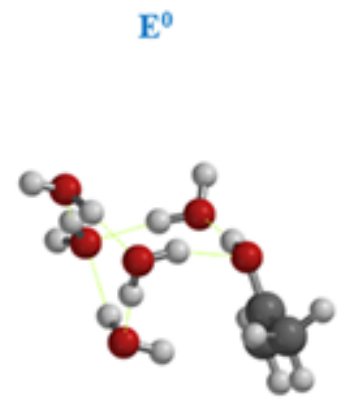

$\mathbf{E}^{5}$

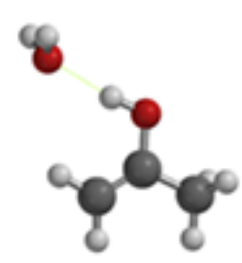

$\mathbf{E}^{1}$

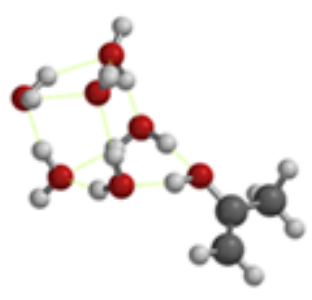

$\mathbf{E}^{6}$

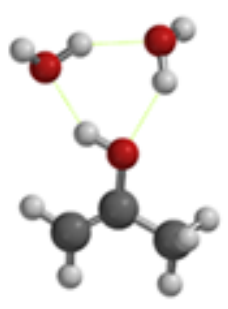

$\mathbf{E}^{2}$

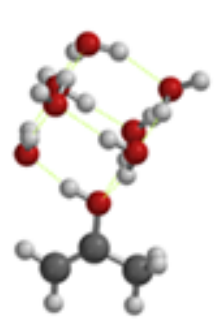

$\mathbf{E}^{7}$

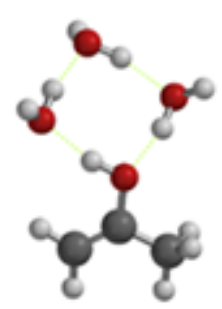

$\mathbf{E}^{3}$

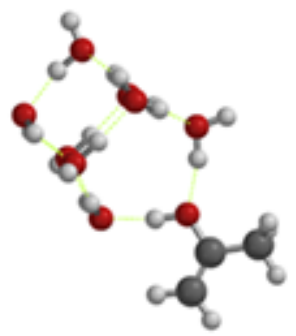

$\mathbf{E}^{s}$

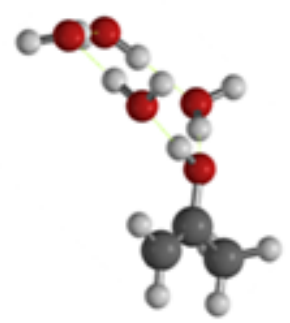

$\mathbf{E}^{4}$

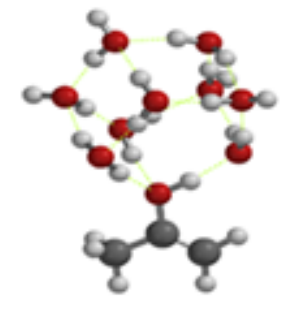

$\mathbf{E}^{9}$

\section{Figure 3}

The structures of E-WC assemblies in the gas phase, En, $n$ : number of water molecules of WC; $n=0-9$.

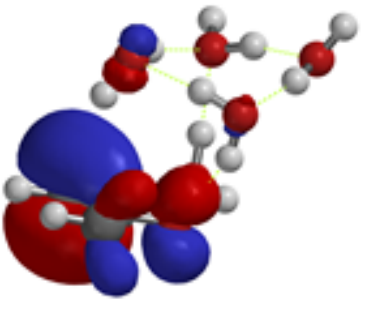

Figure 4

The HOMO orbital of E5 


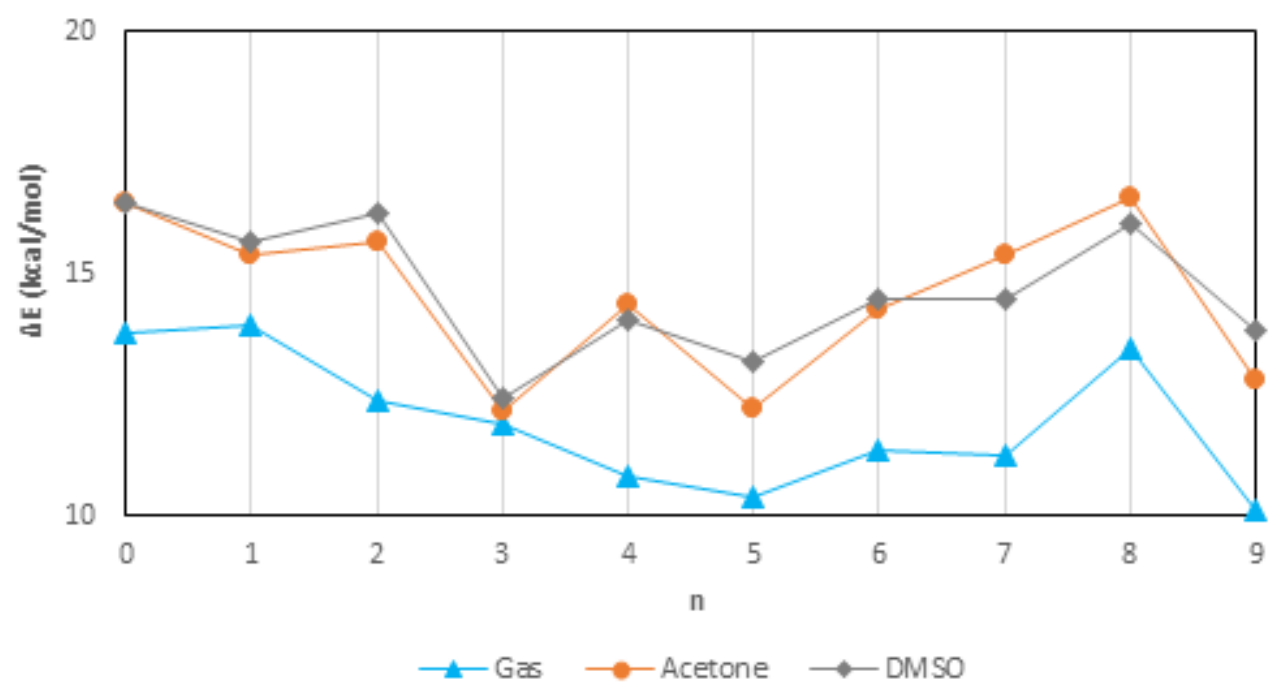

(a)

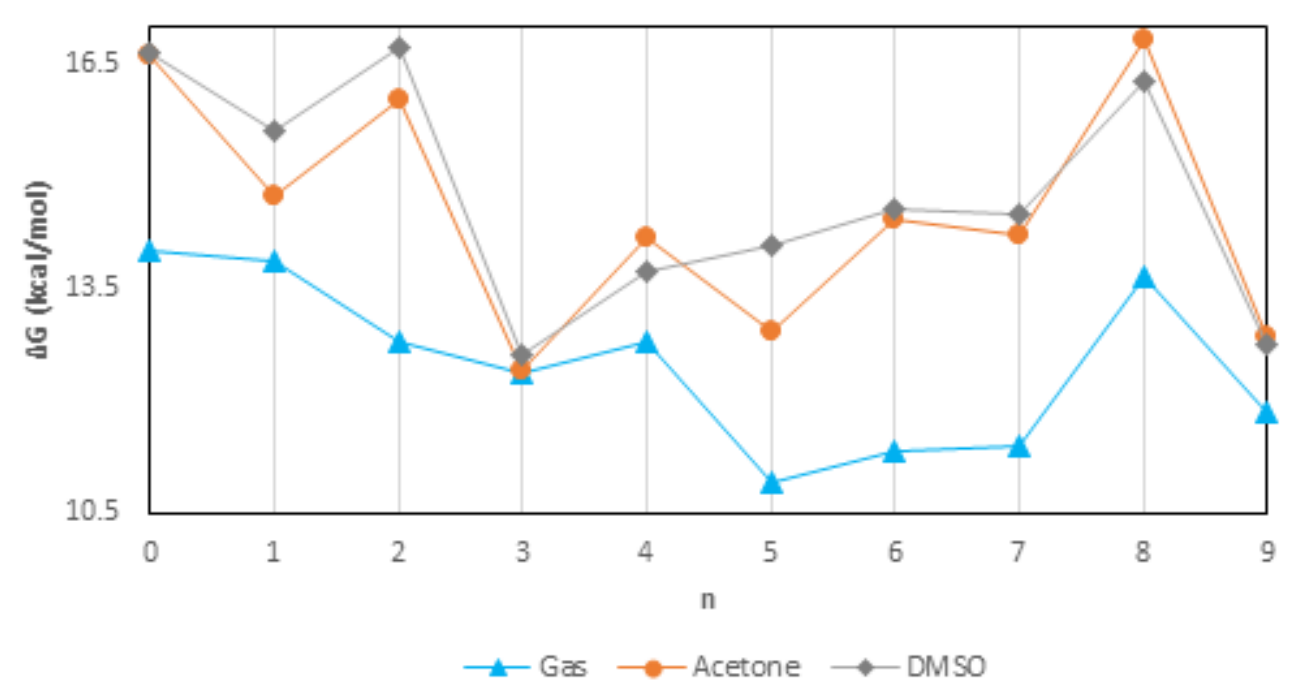

(b)

\section{Figure 5}

a) Energy difference $(\Delta E)$ and b) Gibbs free energy difference $(\Delta G)$ of Kn and En vs. the number of water molecules $(n)$ in the assembly, at the $M 06 / 6-31+G^{* *}$ level of theory 


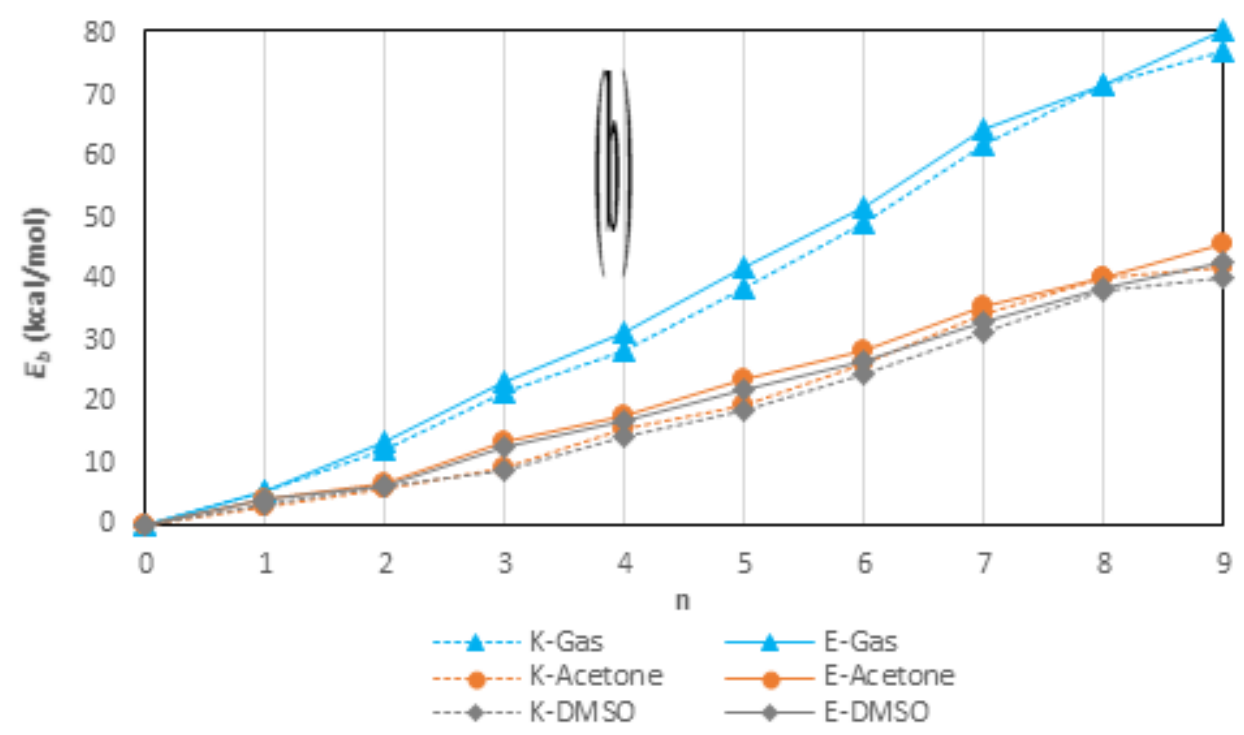

(a)

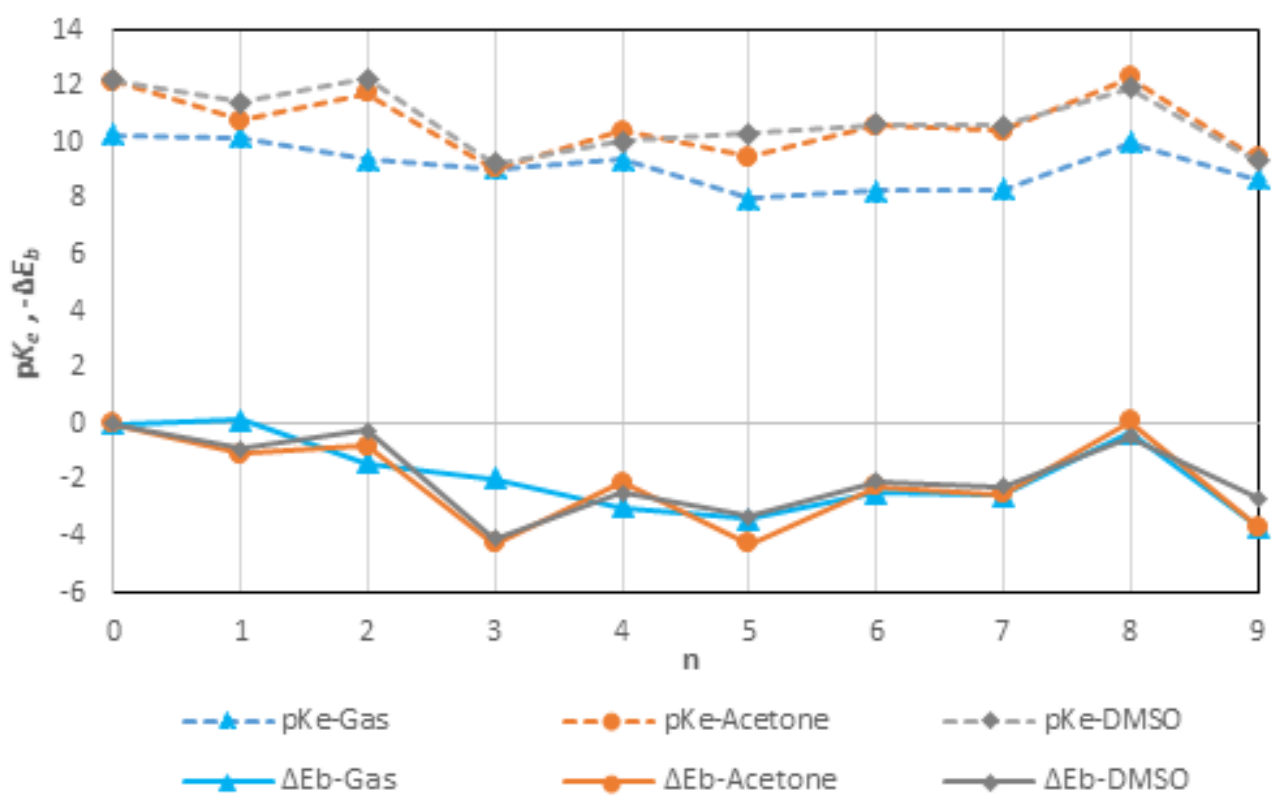

(b)

\section{Figure 6}

(a) The binding energy of water-clustered tautomers $(\mathrm{Eb})$ and $(\mathrm{b})$ the binding energy difference of them ($\Delta \mathrm{Eb})$ and $\mathrm{pKe}$ values in the gas and solution phases as a function of the number of water molecules ( $\mathrm{n}$ ) in the assembly, calculated at the M06/6-31+G** level of theory

\section{Supplementary Files}

This is a list of supplementary files associated with this preprint. Click to download. 
- G.Abstract.jpg

- Supportinginformation.pdf

Loading [MathJax]/jax/output/CommonHTML/jax.js 